\title{
Correlation of tear clearance rate and fluorophotometric assessment of tear turnover
}

\author{
Ke-Ping Xu, Kazuo Tsubota
}

\begin{abstract}
Background-The study sought to determine dynamic changes and theoretical bases of a clinical diagnostic test, the tear clearance rate.

Methods-Thirty four healthy subjects ranging in age from 22 to 84 years underwent examination of tear clearance rate, the Schirmer test with anaesthesia, as well as fluorophotometric measurement of tear turnover, tear volume, and tear flow. By applying $0.5 \%$ fluorescein into the conjunctival sac and subsequently measuring colour fades on a Schirmer strip, the tear clearance rate for assessing tear drainage was divided into nine grades. The results of the tear clearance rate were compared with those of the basal tear turnover and tear flow obtained from fluorophotometry.

Results-Significant relations were found between the tear clearance rate and the basal tear turnover or tear flow $(r=0.91$ and 0.79 , respectively, $p=0.0001$ ). Considering the grades of progression from low to high, each grade of tear clearance rate showed a $12.5 \%$ increase in basal tear turnover $(3.59 \% / \mathrm{min})$ and tear flow $(0.38 \mu 1 / \mathrm{min})$. There was no significant correlation between age and the basal tear turnover, tear volume, tear flow, or the tear clearance rate.

Conclusion-The tear clearance rate is proposed as a simple and useful way to estimate basal tear turnover and tear flow, and measure tear drainage indirectly. (Br f Ophthalmol 1995; 79: 1042-1045)
\end{abstract}

The Schirmer test for assessing a hyposecretion of tears is well known clinically despite its lack of precision and stability. Other techniques for estimating tear flow are based on the introduction of dye into the conjunctival sac with a subsequent determination of the rate at which the colour fades in the fluid. ${ }^{12}$ The tear clearance rate has been combined with the Schirmer test with anaesthesia to evaluate decreased tear production, ${ }^{3}$ and is used mainly in estimating tear drainage. However, it is not clear whether this method can show dynamic changes in the tear flow. Following a decay of fluorescein concentration in tears, tear turnover can be determined fluorophotometrically, which provides an indirect quantitative assessment of tear production. ${ }^{4-9}$ Tear turnover is the percentage decrease per minute of fluorescein concentration in tears after the instillation of fluorescein. Fluorophotometric measurements given without topical anaesthesia have shown two phases of tear production, an initial fast phase caused by reflex lacrimation and a subsequent slow phase caused by physiological or basal lacrimation. ${ }^{4-8}$ In order to standardise the tear clearance rate and identify its value in assessing tear drainage, we measured tear flow without anaesthesia using an objective fluorophotometer, and compared the results with those of the tear clearance rate.

\section{Participants and methods}

\section{SUBJECTS}

The study group comprised 34 healthy individuals (mean age 58.4 (SD 14.7) years, ranging from 22 to 84 years). Tear turnover was determined in 55 eyes of the subjects. They were examined by slit-lamp microscope without fluorescein to ensure there were no corneal epithelial lesions. Subjects who wore contact lenses, had ocular abnormalities, or systemic diseases related to tear secretion were excluded. Informed consent was obtained from all subjects before the study.

\section{INSTRUMENTATION}

Fluorophotometric measurements were carried out with an FM-500 laser flare meter (Kowa Company Ltd, Japan), consisting of a slit-lamp and a photometric microscope. Light from the fluorescein solution passes through green barrier filters to a photomultiplier whose output can be read on a computerised display. The instrument was adjusted to scan linearly at a $30^{\circ}$ angle between the optical axis of the eye and the excitation beam, and at a $60^{\circ}$ angle between the optical axis of the eye and the photometric microscope. The tear film meniscus was measured at the centre of the lower lid margin.

MEASUREMENT PROCEDURE

Autofluorescence of the tear film meniscus was obtained from each eye before fluorophotometry. A $1 \mu \mathrm{l}$ drop of $0.005 \%$ sodium fluorescein $(50 \mu \mathrm{g} / \mathrm{ml}$ ) was then instilled into the upper lateral part of the bulbar conjunctiva without touching the eye. The subject was asked to blink with no squeezing so as to homogenise the fluorescein over the tear film. The eye was scanned in a dark room by fluorophotometer every minute for 5 minutes, and subsequently every 1.5 minutes for 12 minutes. The Schirmer test with anaesthesia and the tear clearance rate were administered 1 hour after the fluorophotometric measurement. A $10 \mu \mathrm{l}$ drop of $0.5 \%$ fluorescein and $0.4 \%$ oxybuprocaine hydrochloride was instilled into the 


\section{Schirmer \& Clearance Test}

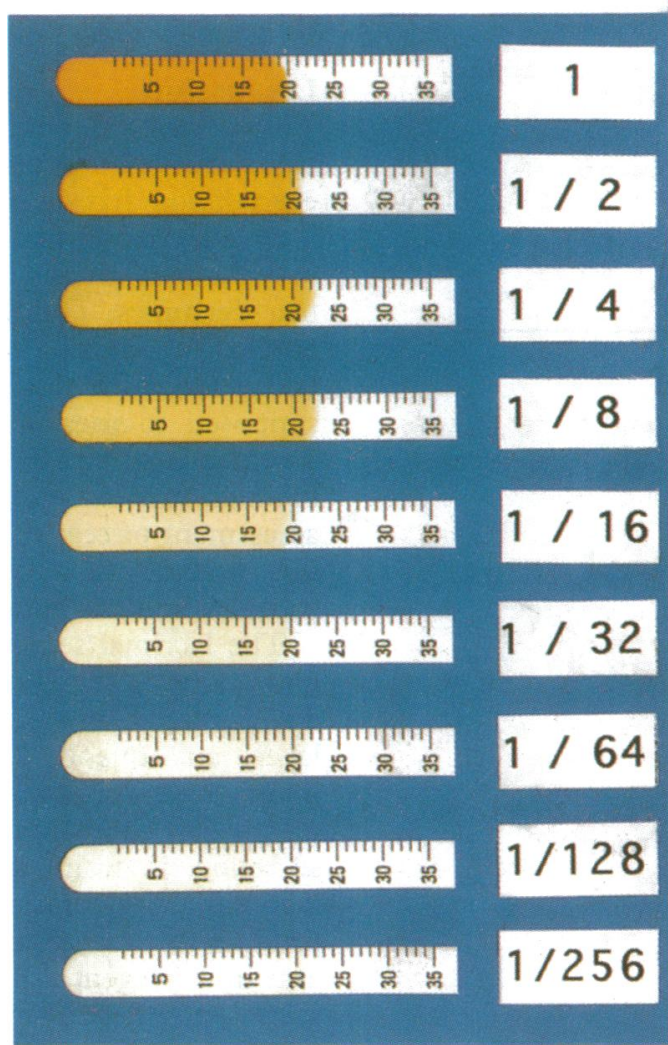

Figure 1 Standard colour plate of the tear clearance rate.

conjunctival sac. Subjects were asked to open their eyes for 5 minutes. Standard Schirmer strips were inserted with both eyes closed for another 5 minutes. The length of the wet portion was measured and the intensity of the staining was compared with a standard colour plate for the Schirmer test with anaesthesia or the tear clearance rate. ${ }^{3}$ The latter was determined by the rate at which colour of the $0.5 \%$ fluorescein faded, and graded as $1,1 / 2,1 / 4$, $1 / 8,1 / 16,1 / 32,1 / 64,1 / 128$, or 1/256 (Fig 1).

\section{DATA PROCESSING}

Fluorescence values were corrected for autofluorescence so as to get relative fluorescein concentration in tears. The fluorescein concentration equivalent (FCE $(\mathrm{ng} / \mathrm{ml})$ ) is obtained from values of the photon count (per ms).

$\mathrm{FCE}=2.42 \times$ photon count

Basal tear turnover was determined from values of the fluorescein concentration measured 5 minutes after instillation. The fluorescein concentration in the first 5 minutes was influenced by reflex lacrimation and determined as initial tear turnover (Fig 2). Tear turnover is a decay of fluorescein concentration in terms of a single exponential. The fluorescein concentration in tear film, $C_{t}(n g / m l)$, at time $(t)$ is given by ${ }^{4}$ :

$$
C_{t}(t)=C_{t}(0) e^{\delta t}
$$

$\delta$, a decay constant of the tear fluorescence per minute, can be calculated from the curve of the fluorescence decay by exponential regression to the data points. Tear turnover, $T_{t}(\% / \mathrm{min})$, at each minute (t1) after the instillation of

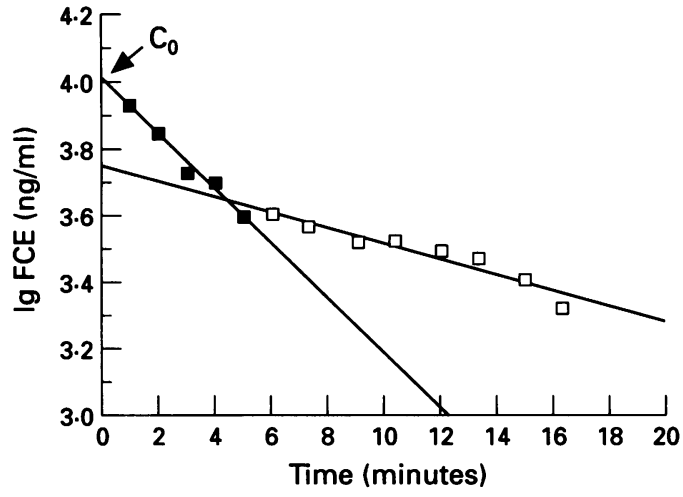

Figure 2 Plot of fluorescein concentration equivalent (FCE, ng/ml) versus time (minutes). The initial turnover rate was obtained by a single exponential regression to the data points of the first 5 minutes (closed squares). The basal turnover rate was calculated by an exponential regression to the data points measured after 5 minutes (open squares). Fluorescein concentration at time $0, C_{0}(\mathrm{ng} / \mathrm{ml})$, was obtained from regression line of the initial turnover rate at time 0 (arrow).

fluorescein, is expressed as a decreasing percentage of fluorescein concentration in tears ${ }^{8}$ :

$$
T_{t}(t 1)=100\left(1-e^{\delta 1}\right)
$$

Tear volume, $V_{t}(\mu l)$, is determined from drop volume, $V_{d}(\mu l)$, fluorescein concentration in the drop, $\mathrm{C}_{\mathrm{d}}(\mathrm{ng} / \mathrm{ml})$, and fluorescein concentration at time $0, \mathrm{C}_{0}(\mathrm{ng} / \mathrm{ml})^{48}$

$$
\mathrm{V}_{\mathrm{t}}=\mathrm{V}_{\mathrm{d}}\left(\mathrm{C}_{\mathrm{d}} / \mathrm{C}_{0}-1\right)
$$

This equation is valid only when initial fluorescein concentration in tears is mixed well without any loss. The value of $\mathrm{C}_{0}$ is determined from the intercept of exponential regression at time 0 (Fig 2). Tear flow, $F_{t}(\mu 1 / \mathrm{min})$, under physiological conditions is estimated from basal tear turnover, $\mathrm{T}_{\mathrm{t}}(\% / \mathrm{min})$, and tear volume, $V_{t}(\mu l)^{4}$ :

$$
\mathrm{F}_{\mathrm{t}}=\mathrm{T}_{\mathrm{t}} \times \mathrm{V}_{\mathrm{t}} / 100
$$

\section{STATISTICAL ANALYSIS}

STAT VIEW software (1988 Abacus Concepts, Inc) was used for the determination of Student's $t$ test, correlation, and regression. A level of $\mathrm{p}<0.05$ was considered statistically significant.

\section{Results}

The basal tear turnover in healthy subjects with a mean age of 58.4 (SD 14.7) years was 10.7 (SD 8.0) $\% / \mathrm{min}$, and the tear volume 9.7 (SD 4.2) $\mu$ l. Thus, the tear flow obtained from the basal tear turnover and tear volume was $1 \cdot 1$ (SD 1.0$) \mu \mathrm{l} / \mathrm{min}$. Table 1 shows the mean of the basal tear turnover, tear volume, and tear flow in each grade of the tear clearance rate. There were significant relations between the tear clearance rate and the basal tear turnover or tear flow $(r=0.91$ and 0.79 , respectively, $\mathrm{p}=0.0001$, Fig 3). Each grade of the tear clearance rate showed a $12.5 \%$ increase in the basal tear turnover $(3.59 \% / \mathrm{min})$ and tear flow $(0.38 \mu \mathrm{l} / \mathrm{min})$ in progressing from low to high clearance rate as calculated from the linear equations $y=3.598 x-2.738$ and $y=0.381 x$ -0.361 , respectively (Fig 3 ). No significant correlation was found between the tear clearance rate and the tear volume $(r=0 \cdot 02)$. There 
Table 1 Tear clearance rate and results (SD) of fluorophotometric assessment in 55 eyes of healthy subjects

\begin{tabular}{lcccc}
\hline $\begin{array}{l}\text { Tear clearance } \\
\text { rate }(\text { grade) }\end{array}$ & $\begin{array}{l}\text { Number } \\
\text { of eyes }\end{array}$ & $\begin{array}{l}\text { Basal tear turnover } \\
(\% / \text { min) }\end{array}$ & $\begin{array}{l}\text { Tear volume } \\
(\mu l)\end{array}$ & $\begin{array}{l}\text { Tear flow } \\
(\mu / \text { min })\end{array}$ \\
\hline 1 & 3 & $1 \cdot 4(1 \cdot 2)$ & $10 \cdot 8(5 \cdot 2)$ & $0 \cdot 1(0 \cdot 1)$ \\
$1 / 2$ & 3 & $1 \cdot 3(0 \cdot 3)$ & $9 \cdot 3(0 \cdot 6)$ & $0 \cdot 1(0)$ \\
$1 / 4$ & 11 & $3 \cdot 1(1 \cdot 1)$ & $11 \cdot 1(5 \cdot 5)$ & $0 \cdot 3(0 \cdot 2)$ \\
$1 / 8$ & 11 & $8 \cdot 1(1 \cdot 5)$ & $8 \cdot 4(2 \cdot 3)$ & $0 \cdot 7(0 \cdot 3)$ \\
$1 / 16$ & 9 & $10 \cdot 9(3 \cdot 7)$ & $8 \cdot 3(5 \cdot 1)$ & $1 \cdot 0(0 \cdot 7)$ \\
$1 / 32$ & 4 & $15 \cdot 6(2 \cdot 0)$ & $8 \cdot 6(2 \cdot 3)$ & $1 \cdot 3(0 \cdot 3)$ \\
$1 / 64$ & 6 & $17 \cdot 5(1 \cdot 9)$ & $8 \cdot 4(2 \cdot 7)$ & $1 \cdot 5(0 \cdot 6)$ \\
$1 / 128$ & 8 & $24 \cdot 0(6 \cdot 1)$ & $11 \cdot 6(5 \cdot 3)$ & $2 \cdot 7(1 \cdot 2)$ \\
$1 / 256$ & 0 & - & - & - \\
\hline
\end{tabular}
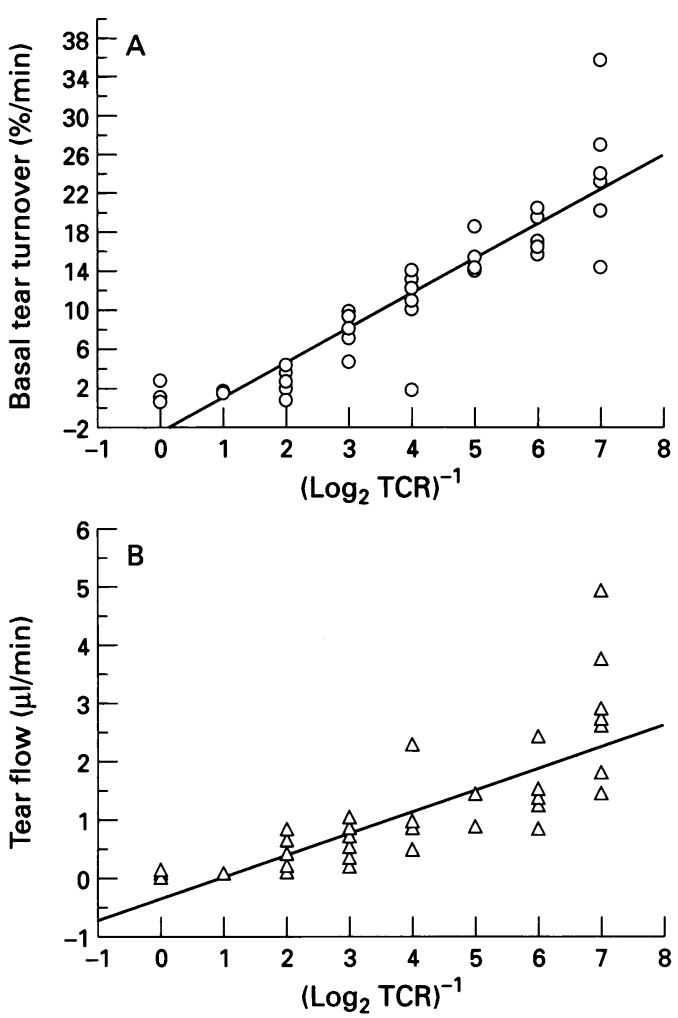

Figure 3 Relations between the tear clearance rate (TCR) (logarithmic form) and the basal tear turnover $(A)$ or tear flow $(B)$ were obtained from single regressions. Each tear clearance rate showed a $12.5 \%$ increase in basal tear turnover $(3.59 \% / \mathrm{min})$ and tear flow $(0.38 \mu \mathrm{l} / \mathrm{min})$ in progressing from low to high grades.

were also no significant relations between age and the basal tear turnover, tear volume, tear flow, or results of the tear clearance rate $(r=0 \cdot 10,0 \cdot 17,0 \cdot 20$, and $0 \cdot .16$, respectively). Results of the Schirmer test with anaesthesia were divided into two groups according to clinical criteria for assessing tear secretion (Table 2). Although the mean value of the Schirmer test with anaesthesia in the group of $\leqslant 8(\mathrm{~mm})$ was significantly lower than that in the group of $>8(\mathrm{~mm}, \mathrm{p}=0.0001)$, a significant difference between their tear volumes was not observed $(p=0.34)$. There were also few correlations between the values of the Schirmer test with anaesthesia and the basal tear turnover,

Table 2 Comparison of the Schirmer values with anaesthesia and the tear volume determined by fluorophotometry in 55 eyes of healthy subjects

\begin{tabular}{|c|c|c|c|c|c|}
\hline $\begin{array}{l}\text { Schirmer value } \\
(\mathrm{mm} / 5 \mathrm{~min})\end{array}$ & $\begin{array}{l}\text { Number } \\
\text { of eyes }\end{array}$ & $\begin{array}{l}\text { Mean }(S D) \text { of Schirmer } \\
\text { values }(\mathrm{mm} / 5 \mathrm{~min})\end{array}$ & $p$ Value ${ }^{\star}$ & $\begin{array}{l}\text { Mean }(S D) \text { of } \\
\text { tear volumes }(\mu l)\end{array}$ & p Value ${ }^{\star}$ \\
\hline $\begin{array}{l}>8 \\
\leqslant 8\end{array}$ & $\begin{array}{l}14 \\
41\end{array}$ & $\begin{array}{r}19 \cdot 5(8 \cdot 3) \\
4 \cdot 3(2 \cdot 1)\end{array}$ & 0.0001 & $\begin{array}{l}9 \cdot 2(3 \cdot 8) \\
9 \cdot 9(4 \cdot 3)\end{array}$ & 0.34 \\
\hline
\end{tabular}

^Statistical analysis from Student's $t$ test, two tailed. tear volume, or tear flow $(r=0.01,0.09$, and 0.05 , respectively).

\section{Discussion}

Tear dynamics consists of three components: tear secretion, evaporation, and drainage. Tear evaporation has been discussed elsewhere. ${ }^{10}$ Tear secretion or tear drainage cannot be evaluated independently of the other two factors in tear dynamics. The Schirmer test is primarily applied in assessing tear production. A modified form of the test given with anaesthesia is supposed to measure basic tear secretion. ${ }^{11}$ The tear clearance rate as an extended form of the Schirmer test with anaesthesia involves the assessment of tear drainage. It is evident that this method is of value in estimating tear turnover and tear flow.

The lacrimal secretory system involves two parts: a basic secretion and a reflex secretion. The former consists of secretion of a mucous layer, an aqueous layer, and an oil layer, mainly the secretion from accessory lacrimal glands of Kraus and Wolfring. The reflex secretion is from the main and accessory lacrimal glands. Basic tear secretion alone can produce three layers of the precorneal tear film and thus prevent a dry eye. ${ }^{12}$ However, such secretion independent of reflex tearing was questioned. Numerous stimuli (such as psychogenic and sensory) may influence the basic tear secretion. ${ }^{13}$ On the other hand, the existence of physiological tear flow relies on such stimuli to some extent. ${ }^{14}$

The introduction of dye into the conjunctival sac and the determination of the rate at which the colour fades can be evaluated by both the Schirmer strip and a fluorophotometer. ${ }^{15}$ The grade of tear clearance rate defined from 1 - the colour of undiluted $0.5 \%$ fluorescein solution, to $1 / 256$ - no apparent staining on Schirmer strip, is based on titre changes of the fluorescein concentration in the conjunctival sac. Coincidentally, fluorophotometry for determining tear turnover and tear flow is based on fluorescence decay in the tear film. In both situations fluorescein concentration changes have two prerequisites - no obstruction of the lacrimal drainage passage and continuous production of the tear flow. Tear clearance rates in anaesthetised eyes and basal tear turnover in unanaesthetised eyes are supposedly the same when assessing basic tear flow. In the present study, the grades of tear clearance rate in vivo have shown variation in the basal tear turnover or tear flow assessed by fluorophotometry. Thus, the tear clearance rate offers a simple way to determine tear drainage and/or tear production while measuring Schirmer value, and estimating tear turnover and/or tear flow when a fluorophotometer is not available.

That tear volume does not correlate with the tear clearance rate is not unreasonable since tear production may not be the only factor determining tear drainage. Other factors such as tear evaporation and tear drainage forces also interfere with tear drainage. ${ }^{4}$ Variation in forces affecting tear drainage is reflected in 
values of the Schirmer test with anaesthesia and the tear clearance rate. A high tear clearance rate may be accompanied by a low Schirmer value if the drainage forces are strong. ${ }^{3}$ This phenomenon was also observed in a previous study where high tear turnover rates were found in eyes having low Schirmer test results, and vice versa. ${ }^{5}$ In addition, tear volume assessed by fluorophotometry did not differ in two groups having a significant difference in Schirmer values, indicating that other factors, probably tear drainage, may produce an impact on Schirmer values. Thus, lack of correlation between the Schirmer value and the basal tear turnover, tear volume, or tear flow is not surprising. The basal tear turnover in healthy subjects in this study is 10.7 (SD $8 \cdot 0) \% / \mathrm{min}$, slightly lower than $15-16 \% / \mathrm{min}$ reported by Mishima and others ${ }^{4} 68$ but within the $95 \%$ confidence limit of $5-30 \% / \mathrm{min} .{ }^{6}$ The average tear volume (9.7 (SD 4.2) $\mu \mathrm{l})$ and tear flow $(1 \cdot 1(\mathrm{SD} 1 \cdot 0) \mu / \mathrm{min})$ are similar to those reported previously. 48 These suggest that the measurement procedures applied in this study are relatively reliable. That tear production does not decrease with advancing age is consistent with results of the other studies. 46816 An age dependency of tear production found in the Schirmer test was probably induced by insertion of the Schirmer strip even after topical anaesthesia. Using the non-invasive measurement of fluorophotometry, reflex tear production was not present at an appreciable level. Possible sources of error in the measurements include excessive blinking after instillation of the fluorescein solution and stimulation from Schirmer strip and light. Although most subjects blinked gently so that fluorescein would be mixed well without loss, some subjects squeezed their eyes before fluorophotometric measurement and part of the fluorescein stuck to the margins of the eyelids. These (13) eyes were excluded from the calculation. In the study we intended that reflex tearing be diminished as far as possible. Although irritation was minimised after topical anaesthesia, stimulation from Schirmer strip to lid margin may not reflect basic tear secretion independent of reflex tearing. ${ }^{13}$ Besides, light can cause reflex tearing ${ }^{11} 17$ both in measuring fluorophotometry and tear clearance rate or the Schirmer test with anaesthesia. The present study demonstrates that tear clearance rate is of value in estimating the basal tear turnover or tear flow. With a properly functioning exit pathway, tear drainage, mainly the basal tear turnover or tear flow, can be evaluated by the tear clearance rate.

This work was supported by the Uehara Memorial Foundation, Tokyo, Japan.

1 Zappia RJ, Milder B. Lacrimal drainage function: 1. The Jones fluorescein test. Am $\mathcal{f}$ Ophthalmol 1972; 74: $154-9$.

2 Zappia RJ, Milder B. Lacrimal drainage function: 2. The fluorescein dye disappearance test. Am $\mathcal{f}$ Ophthalmol 1972; 74: 160-2.

3 Xu K-P, Yagi Y, Toda I, Tsubota K. Tear function index: a new measure of dry eye. Arch Ophthalmol 1995; 113: 84-8.

4 Mishima S, Gasset A, Klyce SD Jr, Baum JL. Determination of tear volume and tear flow. Invest Ophthalmol Vis Sci 1966; 5:264-76.

5 Occhipinti JR, Mosier MA, LaMotte J, Monji GT Fluorophotometric measurement of human tear turnover Fluorophotometric measurement of hum

6 Puffer MJ, Neault RW, Brubaker RF. Basal precorneal tear turnover in the human eye. Am $\mathcal{F}$ Ophthalmol 1980; 89: 369-76.

7 Stolwijk TR, van Best JA, Lemkes HHPJ, de Keizer RJW, Oosterhuis JA. Determination of basal tear turnover in insulin-dependent diabetes mellitus patients by fluorophotometry. Int Ophthalmol 1991; 15: 377-82.

8 Kuppens EVMJ, Stolwijk TR, de Keizer RJW, van Best JA. Basal tear turnover and topical timolol in glaucoma patients and healthy controls by fluorophotometry. Invest patients and healthy controls by fluorop

9 Maurice DM. A new objective fluorophotometer. Exp Eye Res 1963; 2: 33-8.

10 Tsubota K, Yamada $M$. Tear evaporation from the ocular surface. Invest Ophthalmol Vis Sci 199.2; 33: 2942-50.

11 Duke-Elder S. Disorders of secretion. In: Duke-Elder S, ed. System of ophthalmology. Vol 4. London: Henry Kimpton, 1968: 596-7.

12 Jones LT. The lacrimal tear system and its treatment. Am f Ophthalmol 1966; 62: 47-60.

13 Jordan A, Baum J. Basic tear flow: does it exist? Ophthalmology 1980; 87: 920-30.

14 Cross DA, Krupin T. Implications of the effects of general anesthesia on basal tear production. Anesth Analg 1977; 56: $357-67$.

15 Duke-Elder $S$. The rate of flow of tears. In: Duke-Elder $S$, ed. System of ophthalmology. Vol 4. London: Henry Kimpton, 1968: 424-5

16 Lamberts DW, Foster CS, Perry HD. Schirmer test after topical anesthesia and the tear meniscus height in normal eyes. Arch Ophthalmol 1979; 97: 1082-5.

17 Clinch TE, Benedetto DA, Felberg NT, Laibson PR Schirmer's test: a closer look. Arch Ophthalmol 1983; 101: 1383-6. 